\title{
SÍMBOLOS E RITUAIS NA AQUISIÇÃO DA CASA PRÓPRIA EM CONDOMÍNIOS-CLUBE ${ }^{1}$
}

\section{Paula Alexandra Gil ${ }^{2}$}

Angela da Rocha $^{3}$

Ana Raquel Coelho Rocha ${ }^{4}$

http://dx.doi.org/10.1590/1413-2311.308.101926

\section{RESUMO}

Este trabalho investiga de que forma consumidores pertencentes à nova classe média atribuem significado à aquisição da casa própria em condomínios multi-familiares. Adotou-se uma perspectiva interpretativa, embasada nos pressupostos teóricos da Consumer Culture Theory. A pesquisa se baseou em entrevistas qualitativas com compradores de imóveis pertencentes a este segmento da população, cuja aquisição ocorreu nos cinco anos anteriores à realização do trabalho de campo. Utilizou-se a análise de conteúdo qualitativa como método de análise dos dados e as categorias de análise utilizadas emergiram do campo. Os resultados obtidos indicam que tanto a casa própria quanto as áreas comuns compartilhadas nos condomínios são representadas de distintas formas. Além disso, o estudo mostra de que forma os informantes articulam uma organização simbólica desses espaços, construída em torno da dicotomia casa / rua, com suas áreas de mediação.

\footnotetext{
${ }^{1}$ Recebido em 13/4/2020, aceito em 2/12/2020.

${ }^{2}$ Pontifícia Universidade Católica do Rio de Janeiro; Rio de Janeiro (RJ) - Brasil; http://orcid.org/0000-00025645-7902; paula.alexandra.gil@gmail.com.

${ }^{3}$ Pontifícia Universidade Católica do Rio de Janeiro; Rio de Janeiro (RJ) - Brasil; https://orcid.org/0000-00016651-0933; angelarocha@iag.puc-rio.br

4 Universidade Federal Fluminense - Departamento de Ciências Administrativas; Niterói (RJ) - Brasil; https://orcid.org/0000-0002-0478-5146; anaraquelrocha@id.uff.br.
} 
Palavras-chave: Casa Própria; Nova Classe Média Emergente; Consumo Simbólico; Consumidores Emergentes.

\section{SYMBOLS AND RITUALS IN THE ACQUISITION OF ONE'S HOME IN CLUB CONDOMINIUMS}

This paper investigates how consumers belonging to the new middle class attach meaning to the acquisition of their own home in multi-family condominiums. An interpretative perspective was adopted, based on the theoretical assumptions of Consumer Culture Theory. The research was based on qualitative interviews with real estate buyers belonging to this segment of the population, whose acquisition occurred in the five years prior to the realization of the fieldwork. Qualitative content analysis was used as a method of data analysis and the analytical categories used emerged from the field. The results indicate that both the home itself and the common areas shared in the condominiums are represented in different ways. In addition, the study shows how informants articulate a symbolic organization of these spaces, built around the home / street dichotomy, with their mediation areas.

Keywords: Home; New Emerging Middle Class; Symbolic Consumption; Emerging Consumers.

\section{SÍMBOLOS Y RITUALES EN LA ADQUISICIÓN DE LA CASA PROPIA EM CONDOMINIOS-CLUB}

Este artículo investiga cómo consumidores que pertenecen a la nueva clase media atribuyen significado a la adquisición de su propia casa en condominios multifamiliares. Se adoptó una perspectiva interpretativa, basada en los supuestos teóricos de la Consumer Culture Theory. La investigación se basó en entrevistas cualitativas con compradores de bienes inmuebles pertenecientes a este segmento de la población, cuya adquisición se produjo en los cinco años anteriores a la realización del trabajo de campo. El análisis de contenido cualitativo se utilizó como método de análisis de datos y las categorías de análisis utilizadas surgieron del campo. Los resultados obtenidos indican que tanto el hogar como las áreas comunes compartidas en los condominios están representados de diferentes maneras. Además, el estudio muestra cómo los informantes articulan una organización simbólica de estos espacios, construidos alrededor de la dicotomía casa / calle, con sus áreas de mediación.

Palabras clave: Casa propia; Nueva clase media emergente; Consumo simbólico; Consumidores emergentes.

\section{INTRODUÇÃO}


Este estudo adota uma perspectiva interpretativa para buscar entender os significados atribuídos por consumidores emergentes à aquisição da casa própria, inserida em condomínios multi-familiares, considerada uma das decisões mais significativas para o indivíduo e sua família, tanto por seu impacto no orçamento familiar quanto pelos significados que impregnam sua aquisição e desfrute (CASTILHOS; ROSSI, 2009; NERI, 2010).

Nas últimas décadas, milhões de indivíduos ascenderam da pobreza à classe média, não só no Brasil, mas também em outras economias emergentes, passando a se inserir na sociedade de consumo (BAUDRILLARD, 1995). Em novembro de 2015, já sob os efeitos da crise econômica, estimava-se que o estrato social que inclui a chamada "nova classe média" (NERI, 2010) representasse quase 55\% da população brasileira (COSTA, 2016). A partir de 2015, a recessão da economia brasileira levou uma parcela desses consumidores de volta à pobreza, interrompendo seus sonhos de consumo (veja-se, por exemplo, BELLINI e ALVARES, 2018). Estimava-se em meados de 2019, que os $50 \%$ mais pobres tiveram sua renda reduzida em $17 \%$ desde o final de 2014 (NERI, 2019).

Embora esta parcela da população já tenha sido objeto de pesquisas, particularmente no Brasil, identificamos poucos estudos que examinassem o consumo simbólico da nova classe média relacionado à moradia própria. Esta questão é importante, não só pela dimensão atribuída a este estrato populacional no Brasil e em outras economias emergentes, como pelo fato de a literatura de marketing e consumo ter-se voltado predominantemente para o entendimento do consumo das classes mais altas. Nesta linha, Douglas e Isherwood (2013, p.270) observam que "se não sabemos como vivem os pobres, só poderá ser porque os deixamos de fora de nossos rituais de consumo e deixamos de aceitar convites para comparecer aos deles", sugerindo a necessidade de estudos voltados para estratos de renda mais baixa. Outros autores corroboram com esse entendimento, como é o caso de Hemais et al. (2016).

No presente estudo, adotamos a perspectiva teórica da Consumer Culture Theory CCT. Esta perspectiva se ancora em uma tradição multidisciplinar, principalmente conectada à sociologia do consumo e à antropologia do consumo, e constitui uma alternativa à visão da psicologia que impregnou o pensamento de marketing por muitas década. Preocupa-se, fundamentalmente, com os aspectos "socioculturais, experenciais, simbólicos e ideológicos do consumo", retratando "as relações dinâmicas entre as ações do consumidor, o mercado e os significados culturais" (ARNOULD; THOMPSON, 2005, p. 868). Além disso, como salientam 
Casotti e Suarez (2016, p. 357), a pesquisa na CCR é predominantemente indutiva e avança “em domínios que pertencem a diferentes tradições teóricas”.

O consumo simbólico de indivíduos que ascenderam à classe média (por vezes chamados de nova classe média, classe $\mathrm{C}$, baixa classe média, camadas populares, ou consumidores emergentes) já recebeu a atenção de pesquisadores brasileiros. Estudos anteriores abordaram o consumo de produtos, tais como produtos de beleza (MOREL et al., 2016) e automóveis (LODI; HEMAIS, 2019; LUBECK et al., 2014). Também a compra de serviços foi investigada, cobrindo planos de saúde (JULIO; HEMAIS, 2019), educação privada (NASCIMENTO; COSTA FILHO; ALVARES, 2017), lazer (MATTOSO; LIMA; NEVES, 2011; ROCHA; ROCHA; ROCHA, 2016a), produtos culturais (PONTE; MATTOSO, 2014) e varejo (COSTA FILHO; MOTTA, 2015; CUNHA; HEMAIS, 2018; SENNA; HEMAIS, 2017). No entanto, poucos estudos trataram da questão da moradia própria, sendo exceções o de Castilhos e Rossi (2009) e o de Rodrigues (2016). E, no entanto, a aquisição da moradia própria é, possivelmente, o principal sonho de consumo deste segmento (NERI, 2010).

Como explicou Geertz (1973, p. 5), “o homem é um animal suspenso em uma teia de significados que ele mesmo teceu". Assim, a função do cientista social consiste exatamente em buscar entender esses significados e o que eles podem revelar sobre a visão de mundo dos que os compartilham. Nesta linha, estamos interessados em como consumidores emergentes

adquirem um imóvel e o transformam, por meio de rituais de consumo, na "sua casa". Assim, a seguinte questão de pesquisa norteou o estudo: Quais os significados que consumidores emergentes atribuem à aquisição da casa própria e de que forma utilizam os rituais de consumo para realizar a transferência desses significados?

O trabalho encontra-se organizado da seguinte forma: após esta introdução, fazemos uma revisão da literatura sobre consumo simbólico e rituais de consumo. Em seguida, apresentamos os procedimentos metodológicos adotados, com base em entrevistas em profundidade e análise de conteúdo qualitativa. Em seguida, desvendamos, através de uma descrição densa dos resultados, de que forma nossos informantes atribuíram significados à aquisição da casa própria com suas áreas de lazer comuns. Por fim, oferecemos uma visão interpretativa do fenômeno estudado e apresentamos nossas considerações finais.

\section{CONSUMO SIMBÓLICO}


O consumo é, essencialmente, um ato simbólico, "sendo o lócus em que se reafirmam, entre outras questões, identidade, pertencimento, hierarquia, status e poder" (ROCHA; ROCHA, 2007, p.5). Nas sociedades contemporâneas, a posse e uso de bens serve ao indivíduo para comunicar algo sobre si mesmo (DOUGLAS; ISHERWOOD, 2013), o que faz com que o consumo, em seu sentido mais amplo, não deva ser entendido "como uma reação desesperada e necessariamente fútil à experiência da insignificância e sim como uma perfeita solução para a experiência" (CAMPBELL, 2006, p. 63). Por meio do consumo, os indivíduos realizam e expõem suas escolhas e preferências, reforçando sua identidade e consolidando suas posições. Como observa Schmidt (1995, p.8), os indivíduos "constroem, desenham e ordenam o mundo físico por meio de bens", tornando então necessário entender "o significado expressivo dos objetos, o poder simbólico das mercadorias, a qualidade impregnada de significado dos bens".

A forma pela qual se dá o processo de transferência de significados do mundo cultural aos bens e desses aos consumidores foi estudada por McCracken (1986). Os bens derivam seu significado da cultura (ou, na expressão de McCracken, do "mundo culturalmente constituído"), por meio de categorias e princípios culturais de uma sociedade, que servem para organizar e representar o mundo à sua volta, e que são transferidos aos bens por meio da comunicação publicitária e do sistema de moda. A comunicação, por meio de imagens e de expressão verbal, associa produtos a significados. Com relação à moda, a transferência de significados do mundo cultural aos bens ocorre por meio de formadores de opinião, cuja influência se dá em função de sua posição social e características pessoais, desencadeando uma "apropriação imitadora por parte de pessoas de menor status social" (McCRACKEN, 1986, p.76).

Em um segundo movimento, ao adquirirem e usarem os bens, os consumidores transferem suas propriedades simbólicas para si mesmos por meio de rituais de posse, troca, arrumação e despojamento. Os rituais de posse, que incluem particularmente a apresentação e exposição a outros do bem que se passou a possuir, são extremamente importantes no processo de transferência de significado cultural do bem para o indivíduo. Os rituais de arrumação têm uma função semelhante. Incluem o cuidado que o indivíduo tem com objetos e o tempo que lhes é dedicado, tanto para sua conservação, quando para apresentação aos demais. Por meio desses rituais completa-se a transferência do significado incorporado ao bem para quem o adquiriu. Finalmente, os rituais de troca, bastante estudados na literatura de marketing e consumo (por exemplo, ECKHARDT et al., 2015; MICK; DEMOSS, 1990a, 1990b; SHERRY, 1983), referem-se à troca de presentes e os rituais de despojamento expressam a retirada do significado de um bem antes de o consumidor dele se desfazer. 
Esses rituais servem à "manipulação do significado cultural para fins de comunicação e categorização coletiva e individual" (McCRACKEN, 1986, p. 78). Para Douglas e Isherwood (2013), os rituais servem ainda para estabilizar os significados atribuídos aos bens, uma vez que esses significados são fluidos. Rook (1985, p.251) considera a ritualização do consumo "uma dimensão proeminente da experiência do consumidor". Turner (2013), um dos precursores do estudo de rituais na antropologia, fala de rituais de elevação de status, geralmente precedidos de períodos liminares, em que o indivíduo é, de certa forma, desgarrado de sua posição anterior, antes de adquirir a nova. Rocha, Rocha e Rocha (2016b), em um estudo sobre uso de cruzeiros marítimos pela nova classe média brasileira, encontraram a prática de vários rituais de consumo que antecedem o cruzeiro marítimo, ocorrem durante o mesmo, ou são realizados após sua conclusão.

Ao realizar a transferência de significados do bem para si mesmo, o consumidor passa a ver o bem como extensão do eu. Trata-se do conceito de self estendido, proposto por Belk (1988). Para este autor, os bens servem aos consumidores como forma de criar, aumentar e preservar a identidade, não somente em relação a "objetos externos e pertences pessoais, mas também às posses relacionadas a pessoas, lugares e grupos, bem como outros tipos de posses, como partes do corpo e órgãos vitais” (BELK, 1988, p. 140). Este processo, que pode ocorrer tanto em relação a indivíduos quanto famílias e grupos, é essencialmente dinâmico: as mudanças e transições ao longo da vida e os bens que as acompanham exercem influência sobre a construção da identidade (BARBOSA, 2004).

Assim, os bens são sinalizadores, ou seja, realizam "serviços de marcação" (DOUGLAS; ISHERWOOD, 2013). Por isso mesmo, o consumo é um ato público, não privado, já que os significados devem ser compartilhados com outros consumidores. Os bens ocupam uma hierarquia baseada nos significados que lhes foram atribuídos, podendo ser utilizados pelos consumidores como "cercas" ou como "pontes" (p.17), dependendo de se seu propósito é significar integração, classificação ou exclusão.

A questão examinada neste estudo pode ser analisada à luz de estudos sobre espaços de consumo, na literatura de CCT. Como se trata de uma literatura bastante fragmentada, descrita por vezes como uma família de temas e abordagens (ARNOULD; THOMPSON, 2005), encontram-se diferentes enfoques ao tema, desde abordagens funcionais a abordagens críticas. Nosso interesse é nos espaços de consumo como experiências totalizadoras.

A literatura de consumo já examinou diversos desses espaços de consumo, como shopping centers, parques de diversões, resorts, cassinos, cruzeiros marítimos, spas, 
universidades ou até mesmo igrejas. Característica desses espaços é a imersão em uma experiência de consumo acompanhada por uma variedade de serviços (alguns relacionados a lazer, outros a alimentação, além de ampla variedade adicional). Resorts, cruzeiros, spas e parques de diversões podem oferecer, ainda que provisoriamente, o próprio espaço de moradia. São, no entanto, espaços totalizadores, no sentido de criarem possibilidades de imersão - ainda que temporária - em uma totalidade social (SHIELDS, 1992). Em todos esses espaços, há uma segregação em relação ao mundo exterior, e em alguns, como nos parques de diversão, o acesso é estritamente controlado, enquanto nos shoppings ele é simplesmente vigiado. Em todos eles, ainda, ocorre um certo tipo de negociação, implícita ou explícita, para uso dos espaços e para o atendimento, e há códigos de conduta que devem ser seguidos (PATERSON, 2006).

Vários autores examinaram o shopping center como espaço de consumo. O shopping center, ou o mall, como é tratado mais frequentemente na literatura em língua inglesa, é por vezes definido como um "não lugar", por sua descaracterização em relação aos mercados tradicionais, ou visto pela perspectiva da "Disneyficação", como fabricante de ilusões, ou ainda, como mercado-ícone, como discutem Warnaby e Medway (2018). Às vezes nomeados “catedrais de consumo", os malls são vistos por alguns autores como espaços de manipulação capitalista (RITZER; RYAN; STEPNISKY, 2005). Shields (1992) afirma que os benefícios funcionais oferecidos pelo mall são em muito superados por seu valor simbólico e social. Ele salienta ainda o aspecto teatral da experiência de consumo em malls, comparando-os a um palco onde os atores podem ser observados por uma multidão que passa e que não necessariamente compra, mas desfruta o lazer oferecido por esse espaço de consumo.

Os parques de diversão também podem proporcionar uma experiência totalizadora. Paterson (2006), por exemplo, afirma, à luz de outros estudos, que o parque Sea World foi concebido como um espaço de mediação entre o homem e a natureza, construído de forma a domesticá-la e mostrar sua face benigna ao público. No caso dos parques da Disney, o autor afirma que "o resultado é uma sensação de imersão, de ausência de intrusão do mundo exterior" (PATERSON, 2006, p.72).

No caso examinado em nossa pesquisa, os condomínios-clube multi-residenciais, há especificidades, dado que simultaneamente lidamos com um espaço onde se encontram a moradia própria e os espaços de lazer e serviços. Não identificamos, na literatura de consumo, de cunho interpretativo, a abordagem deste espaço, embora deva estar seguramente presente em estudos urbanos. 
Também a literatura internacional que examina o consumo simbólico de moradia é limitada. Para Belk (1988), a casa pode ser equiparada ao corpo: da mesma forma que as roupas vestem o corpo, os objetos vestem a casa. A casa é um local sagrado, em oposição ao mundo externo, ao que é "de fora" (o profano) e é nela que acontecem relações íntimas entre os moradores (BELK, 1988; BELK; WALLENDORF; SHERRY, 1989). A casa é então um dos bens mais significativos para construção da identidade do indivíduo e da família. A casa comunica quem é a família que a habita, por meio de sua localização e de suas características. A relação do indivíduo com a vizinhança também contribui para a construção de sua identidade. Esta relação pode se dar por meio de hierarquização, aceitação ou rejeição.

Ssatcioglu e Ozanne (2013) analisam o simbolismo da moradia própria, ao realizarem um estudo etnográfico sobre trabalhadores residentes em parques de trailers (ou mobile homes) nos Estados Unidos. Neste microuniverso, os autores encontram um processo de hierarquização social, em que mesmo este tipo de moradia aparece como marcador de status, em que os diferenciadores são os valores dos residentes, o cuidado com a limpeza da casa e com sua arrumação, e a relação com os vizinhos. Wang (2016), por sua vez, examina os significados de moradia própria para famílias que ascenderam à baixa classe média na China contemporânea, observando que "a obsessão pela casa própria e o desejo por posses materiais criou uma nova classe de fangnu (escravos da casa), uma classe média com elevados pagamentos de hipotecas". Este comportamento estaria associado à percepção de que, para pertencer à classe média, a família deveria, necessariamente, ser proprietária de um imóvel.

No Brasil, tanto Castilhos e Rossi (2009) quanto Barros e Rocha (2009), embora não abordem diretamente o tema, trazem alguns insights valiosos para o entendimento do significado da moradia e de sua "vestimenta". O estudo de Castilhos e Rossi (2009, p.60) se baseia em uma etnografia realizada em uma favela no Rio Grande do Sul. Os autores apontam que a casa é "o primeiro dos bens valorizados" pela população de baixa renda, significando "ter pelo menos alguma coisa", em oposição à casa alugada e, até mesmo, a ficar ao desabrigo. Há uma hierarquia entre as casas, que tem início na casa própria com escritura, passando pela casa própria inacabada, até chegar à casa de aluguel. Além disso, a casa é, frequentemente, um projeto em construção, a que se agregam, no decorrer do tempo, outros objetos e posses. Além disso, os autores salientam que, no contexto da favela, a fronteira entre a casa e a rua é tênue, sendo a rua o espaço de lazer. Já Barros e Rocha (2009) encontram a inserção religiosa como demarcador de diferenças no consumo entre empregadas domésticas. As consumidoras evangélicas davam maior importância a escolhas de consumo que envolviam "melhoras na 
casa", por espelharem prosperidade e ascensão social da família, em detrimento de gastos com supérfluos.

Mais recentemente, o tema da aquisição da moradia própria foi abordado na dissertação de mestrado de Rodrigues (2016), que examinou a importância da aquisição da casa própria por jovens da baixa classe média pertencentes à geração Y. Além de aspectos inerentes ao processo de compra da casa própria, como preços e localização, o estudo destaca que a aquisição é vista como uma conquista. $\mathrm{O}$ autor mostra também que o principal motivador para a compra do imóvel entre esses jovens costuma ser o início de uma vida conjugal. Por fim, salienta o aspecto hedônico ligado à aquisição, que se expressa nas reformas e na decoração do imóvel. $\mathrm{O}$ autor também identifica um rito de apresentação do imóvel a parentes e amigos. Também a dissertação de mestrado de Ferreira (2006), na área de arquitetura, examina o processo de planejamento e construção de residências unifamiliares em um complexo residencial de São Paulo, sob a perspectiva das famílias, identificando cuidado e detalhamento na personalização do imóvel.

Não se pode deixar de mencionar, em um estudo interpretativo sobre a aquisição da casa própria, a obra de DaMatta (1997), intitulada “A casa e a rua”. Neste trabalho, cuja contribuição se estende para muitas outras de suas obras, DaMatta usa a "casa" e a "rua" como categorias sociológicas complementares para explicar a sociedade brasileira. Embora não pretenda falar dos significados da casa própria, DaMatta tangencia o tema, ao chamar a atenção para o fato de que a casa é um lugar para as "pessoas", aquelas entre as quais existem relações pessoais, e não um lugar para estranhos, ou "indivíduos". Ele comenta que a casa tradicional brasileira dispunha de lugares próprios para receber estranhos, a chamada "sala de visitas", ou, ainda, a varanda que precedia a casa. Dessa forma, ficava protegida a intimidade sagrada da casa da invasão daqueles que não pertenciam ao círculo de relações íntimas e pessoais. No âmbito da casa, impõe-se a harmonia nas relações entre os que ali convivem, e a discórdia deve ser evitada, sendo essa última própria da rua. Mesmo assim, adverte o autor, há espaços na "rua" que podem ser "apropriados", assumindo funções semelhantes aos da casa. E há elementos nas casas e espaços que fazem a mediação entre os dois mundos. Tal é a função das janelas. A rua é vista com suspeita, como lugar de malandros e vigaristas.

\section{METODOLOGIA}


A corrente teórica da Consumer Culture Theory (ARNOULD; THOMPSON, 2005), em que se insere nosso estudo, se caracteriza por uma abordagem interpretativa dos fenômenos do consumo. Tal abordagem permite explorar as múltiplas visões que os consumidores têm do fenômeno pesquisado, traduzindo os significados do consumo da moradia própria e das áreas de lazer em condomínios multifamiliares. Tais significados foram apreendidos por meio do discurso dos informantes.

Buscamos informantes que houvessem adquirido imóveis do Programa Minha Casa Minha Vida nos cinco anos anteriores ao estudo. Este programa foi criado pelo governo federal em 2009, visando reduzir o déficit habitacional brasileiro, sendo voltado para as famílias de baixa renda, atingindo em particular o segmento da nova classe média. $\mathrm{O}$ déficit habitacional brasileiro, que inclui moradias em condições precárias ou desgastadas, ou em situação de coabitação ou aluguel, foi estimado em 2015 (último dado disponível) em 7,7 milhões de unidades, sendo que as faixas de renda mais baixas (até três salários mínimos) respondiam, naquele ano, por quase $92 \%$ do déficit (FJP, 2018). A escolha desse grupo específico responde à recomendação exposta por Casotti e Suarez (2016) da delimitação cuidadosa do contexto de pesquisa.

Foi realizado inicialmente o levantamento de compradores de imóveis inseridos no Programa por meio de registros disponíveis no local de trabalho de uma das pesquisadoras. Foram entrevistados 6 homens e 9 mulheres, a maioria entre 20 e 40 anos (Quadro 1). Quase todos tinham curso superior completo ou incompleto; apenas os dois mais velhos, de 52 e 66 anos, tinham somente o ensino médio. Os nomes dos informantes são fictícios.

Quadro 1: Perfil dos informantes

\begin{tabular}{|l|c|c|l|l|c|}
\hline Nome & Sexo & Idade & \multicolumn{1}{|c|}{ Instrução } & \multicolumn{1}{|c|}{ Profissão } & $\begin{array}{c}\text { No. de moradores } \\
\text { no imóvel }\end{array}$ \\
\hline Brenda & F & 29 & Superior completo & Enfermeira & 1 \\
\hline José & M & 29 & Superior incompleto & Analista comercial & nenhum \\
\hline Diogo & M & 30 & Superior completo & Professor educação física & 2 \\
\hline Fátima & F & 31 & Superior completo & Arquiteta & 3 \\
\hline Luiza & F & 28 & Superior completo & Analista financeiro & 2 \\
\hline Ivone & F & 38 & Superior completo & Arquiteta & 1 \\
\hline Jussara & F & 31 & Superior completo & Arquiteta & 2 \\
\hline Marcelo & M & 31 & Superior incompleto & Analista de crédito & Bióloga \\
\hline Ana & F & 28 & Superior completo & . & 2 \\
\hline
\end{tabular}




\begin{tabular}{|l|c|c|l|l|c|}
\hline Emanuel & M & 38 & Superior completo & Biólogo & 2 \\
\hline Maria & F & 66 & Ensino médio & Supervisora administrativa & 2 \\
\hline Marcia & F & 28 & Superior incompleto & Assistente administrativa & 2 \\
\hline Alex & M & 31 & Superior completo & Professor educação física & 3 \\
\hline Carla & F & 52 & Ensino médio & Aposentada & 1 \\
\hline Lucas & M & 34 & Superior completo & Arquiteto & 1 \\
\hline
\end{tabular}

Os informantes residem na cidade do Rio de Janeiro, em condomínios do Programa Minha Casa Minha Vida, localizados em diversos bairros. É distinta a situação de moradia anterior, mas todos os informantes moraram anteriormente em imóvel alugado ou com outros familiares. Assim, tratava-se da aquisição de seu primeiro imóvel. Os imóveis adquiridos tinham área em torno de $50 \mathrm{~m}^{2}$. O número de unidades residenciais nos condomínios em que os informantes adquiriram imóveis variou entre 160 e 950 unidades.

Utilizamos um roteiro de entrevista semiestruturado, cujo propósito era orientar a entrevista, sem, contudo, impedir que o informante falasse livremente sobre os temas pesquisados. Todas as entrevistas foram presenciais, gravadas com o consentimento dos informantes e depois transcritas.

Foi realizada uma análise de conteúdo qualitativa (CRESWELL, 2010), utilizando categorias de análise para buscar compreender e interpretar os dados colhidos nas entrevistas. Inicialmente, partimos de duas categorias básicas: casa própria e casa alugada, provenientes da literatura. As demais categorias emergiram do campo, à medida que se procedeu à análise de conteúdo. Tal "procedimento indutivo", como salientaram Arnould e Thompson (2007, p.7), "reflete as características da pesquisa de CTT até hoje". Em outras palavras, dado o caráter interpretativo dessa corrente teórica, buscam-se significados que afloram do campo e que possam expressar significados coletivos e identidades construídas e reconstruídas por meio do consumo. Desta forma, as categorias emergentes, na perspectiva interpretativa, se sobrepõem àquelas extraídas da literatura existente, procedimento mais típico dos estudos inseridos no paradigma positivista.

\section{RESULTADOS}


Esta seção fala de dois temas que perpassam o estudo: os significados da moradia própria e os significados do lazer inserido na aquisição da moradia própria. Ao final desta seção, destacamos os aspectos de ritualização identificados na pesquisa.

\subsection{MORADIA PRÓPRIA: ENCONTRANDO, ADQUIRINDO E CRIANDO A CASA}

A lógica de "propriedade" (a que se opõe a "não-propriedade") estabelece o contraste de que partem os informantes para atribuir significados ao bem adquirido. Adquirir a própria casa para evitar morar na casa de parentes, ou em imóvel alugado, aparece recorrentemente no discurso dos informantes. Ser dono de um imóvel próprio significa evitar o aluguel, que é visto como algo "ruim, muito ruim" (Maria), um "sufoco", que impede, de certa forma, fazer da moradia sua casa: "no aluguel, você paga, paga, paga e não vai ter liberdade de fazer umas obras, de fazer aquilo do seu jeito, porque aquela coisa não vai ser sua" (Ana). No aluguel, "você joga dinheiro fora", dinheiro que "não vai ter volta", em troca de algo que nunca será seu (Maria). A compra do imóvel proporciona então segurança e alívio, porque "você não fica com aquilo na cabeça" (Maria), "é uma preocupação a menos" (Diogo), e "permite escapar do sufoco do aluguel" (Ana).

\section{- "Um lugar para chamar de seu"}

O imóvel próprio era uma aspiração e se torna uma conquista pessoal, como explica Marcelo: “Isso daí eu acho que não tem preço. Ah, falar: 'É meu'. Não querendo ser melhor do que ninguém, mas é muito bom. É meu, ninguém toma. Então, isso é muito bom. E encher a boca pra falar que tem. Isso não tem preço.” Marcia descreve a aspiração pela casa própria:

Eu acho que todo mundo quer ter a casa própria. Todo mundo tem uma prioridade. Tem uma listinha de prioridades. Vai colocando, vai enumerando. Pode colocar a casa própria para depois do carro, para depois da faculdade, depois do casamento. Mas no fundo, no fundo, a casa própria queria que fosse lá na frente. Só não quer colocar lá na frente por falta de coragem. Ou de uma oportunidade. Ou por falta de dinheiro.

Por sua vez, Alex fala do esforço e da luta para transformar a aspiração em realidade:

Para mim, é essencial, é uma conquista. Acima de tudo, é uma conquista, porque, por exemplo, eu estudei, eu me formei, tem um passo a passo. Você termina o segundo grau e vai fazer uma faculdade, termina a faculdade e começa a traçar objetivos. Tem o seu trabalho, você guarda dinheiro. Aí seus pais estão propícios a ajudar, e você já pensa: 'Vou comprar alguma coisa, um apartamento'. 
Frequentemente o imóvel próprio é visto como símbolo de uma passagem. Pode significar uma passagem para a vida adulta e a independência dos pais, como no caso de Luiza: "Eu entendo que você precisa seguir sua vida, seu rumo, seu espaço; então, é mais assim a questão da independência, da liberdade e de começo de vida mesmo". O significado de independência apareceu associado a informantes mais jovens, que se encontravam, muitas vezes, na passagem de uma fase de vida a outra, como no caso de casamento ou de morar sozinho, deixando a casa dos pais. Mas o significado de passagem se expressa também no desejo de deixar algo para os filhos. Márcia, desde pequena, "sonhava em ter seu quarto" e, quando cresceu, passou a desejar um imóvel próprio. A chegada de um filho "que não foi planejado" conferiu novos contornos ao desejo de adquirir um imóvel: a possibilidade de “deixar alguma coisa para o meu filho [...] é um legado que eu vou deixar para ele". O pai de Alex o ajudou a adquirir o imóvel com o mesmo propósito: "quero deixar alguma coisa para você". Situação diferente foi vivenciada por Carla. Com o casamento dos filhos, resolveu buscar uma casa que pudesse se adequar ao novo momento de vida: "Eu morava em uma casa de três andares, sozinha e estou envelhecendo. Minha casa é cheia de escadas; queria um lugar mais seguro para mim e pra minha neta."

A narrativa de Lucas, um dos informantes, engloba muitos dos significados construídos na aquisição da casa própria:

\footnotetext{
Eu acho que é o sonho de qualquer cidadão de hoje em dia. A gente cresce aprendendo que precisa comprar um imóvel, um carro. E eu acho que isso era um desejo desde lá trás. Era uma meta a ser definida, uma meta a ser cumprida, na verdade. E aí foi uma das metas batidas. Esse objetivo, esse desejo, é lógico que depois a gente começa a ver, querer mais e mais e mais. Mas eu acho que o desejo era pelo imóvel, de ter algo que é seu de verdade. De ter algo que fosse meu, conquistado com meu trabalho, com meu dinheiro. Para buscar essa satisfação pessoal, entendeu? Eu nunca tinha tido a experiência de morar sozinho, eu morava com os meus pais, então, isso para mim - o imóvel, a compra do imóvel - ele tem uma representatividade na minha vida como se fosse um ponto de partida para um novo ciclo. De independência. Ele tem essa conotação.
}

Por fim, uma única entrevistada, Luiza, equiparou a casa a algo "sagrado".

\section{- "Vamos ver o que dá para pagar"}

Se a aquisição do imóvel próprio é impregnada de significados que transcendem seus aspectos utilitários, o comprador se defronta com questões práticas que cerceiam sua escolha. O imóvel que se compra é "o que dá para pagar". 
Importante determinante para a aquisição do imóvel próprio é poder arcar com o custo, que vai se estender por boa parte da vida do comprador. É a análise do "caber no bolso", como explica Emanuel: "Vou ser sincero, a escolha foi assim: 'dá para pagar'. Porque o primeiro imóvel todo mundo tem ajuda, a gente não, a gente pagou com recursos próprios. Era o que dava para pagar". Marcelo conta que "caber no bolso" foi mais relevante do que a localização. Já a experiência relatada por Maria combina os dois fatores: "Eu escolhi por ser perto e eu já conhecia o local. Estava dentro do meu orçamento; para eu comprar em outro lugar mais movimentado, eu não tinha como. Tudo muito caro". Para Diogo, pesaram o baixo valor do investimento inicial e o valor das prestações mensais, compatíveis com seus rendimentos.

Uma vez "cabendo no bolso", a localização passa a ser um aspecto relevante para a concretização do sonho de aquisição do imóvel próprio. José se sentiu motivado pelas “condições e pelo valor do imóvel”, que "encaixavam [no orçamento]”, e porque o imóvel ficava "próximo aqui ao trabalho". Uma "boa localização", por sua vez, expressa muitas coisas distintas: estar próximo dos pais ou parentes, ter comércio variado, ser próximo do trabalho, ser segura, ou ainda ser uma área familiar ao informante.

Ainda dentro da lógica de restrição, o bem adquirido se distancia frequentemente do ideal, pelo tamanho do imóvel (pequeno), pela área de circulação e outras questões decorrentes do espaço limitado, até outros aspectos, como "a questão, fundamental, de não ter o sol da tarde", o prédio não estar "grudado nos outros" ou a sensação de "segurança 24 horas". Jussara, que queria muito sair da casa dos pais, não se iludia quanto a adquirir o imóvel ideal: "Eu nunca tive muita expectativa do que ele precisava ter. Eu queria na verdade um espaço, como se fosse o meu quarto na casa dos meus pais, um pouco ampliado". No entanto, este aspecto pode trazer limitações para configurações familiares futuras, como no caso da família de Emanuel, que esperava um filho: "Você agora tem que adaptar. Agora com a terceira pessoinha vai ter problema".

Os limitadores acabam sendo justificados pelo fato de o imóvel já "ter tudo" de que se precisa. É a propriedade e o que ela representa, em termos de construção de identidade, que resultam em uma representação por vezes ampliada do que foi adquirido. Como contou Márcia: “Ah, adorei. Tudo. Só de chegar na portaria, eu olho, 'Gente, eu vou morar aqui. É meu'. Não tem nada que me faça desgostar ou [...] 'poderia ter melhorado um pouquinho aqui'. É bem aconchegante. Eu acho a minha cara." O pequeno tamanho do imóvel é então visto por alguns como qualidade e não como defeito: ele é "aconchegante" (Maria e Márcia), "muito jeitosinho" (Emanuel), fácil de limpar (Emanuel), "bem distribuído” (Ivone), “completinho” (Luiza). José 
considera o tamanho do apartamento "suficiente" e "confortável", mas define o conforto por sua negativa: "eu não me sinto apertado, não me sinto espremido".

Algumas características do imóvel adquirido assumem significado particular para os informantes. É o caso da varanda, espaço frequentemente existente em apartamentos voltados para as classes mais altas, mas pouco comuns em construções populares. Brenda vê a varanda como uma abertura para a natureza, para a luz, sugerindo certa liberdade e extensão promovida pelo espaço: "A varanda é a melhor parte, eu acho. Eu gosto muito de natureza, de liberdade; ela dá uma luminosidade maior no ambiente, ela dá uma sensação de mais casa”. Carla, por sua vez, percebe que a varanda descortina a vista, trazendo beleza e aconchego.

\subsection{CONDOMÍNIO-CLUBE: ESTABELECENDO AS FRONTEIRAS DO TERRITÓRIO}

No contexto particular deste estudo, não bastava entender os significados atribuídos à aquisição da casa própria, mas estávamos interessados também em investigar a construção simbólica dos espaços comuns de lazer que acompanham o imóvel. Em geral, inclui salão de festas, playground, piscinas e churrasqueiras, mas pode conter também salão de jogos, academia, quadras de esportes e sauna. A diversidade de áreas de lazer oferecidas varia em função do número de unidades nos condomínios.

Da mesma forma que os significados da casa se constroem em torno da lógica da propriedade, o significado das áreas comuns é entendido como uma extensão da casa. É significativo o trecho do discurso de Ivone: "Se eu não quiser sair de casa nunca mais, ok. Eu vou ficar no meu apartamentinho numa boa, desço, tomo um banho de piscina. Ou, como ali é acessível, posso receber quem eu quiser em casa". Assim, para Ivone, os espaços de lazer do condomínio são apropriados, tornando-se uma extensão de sua casa. Carla acrescenta aos espaços a disponibilidade de "amigos": "Eu não preciso me deslocar. Eu tenho academia, eu tenho churrasqueira, eu tenho piscina, eu tenho sauna, eu tenho salão de jogos e esse monte de amigos, que a gente divide isso tudo. Eu não quero mais nada". Esta afirmativa mostra, por um outro ângulo, que o condomínio tem alguma continuidade com a casa, já que no condomínio, como na casa, trata-se de pessoas, “amigos”, e não de estranhos. Mais adiante veremos que nem sempre é assim.

\section{- "Ninguém vai entrar"}


Um primeiro indício de que a demarcação de fronteiras entre a casa e o "mundo lá fora" inclui o condomínio-clube é a questão da segurança, que se apresenta como principal benefício para os informantes. A segurança do condomínio, como da casa, consiste em separar o que é “de dentro" e o que é "de fora". Nas palavras de Luiza: “Apesar do entorno não ser bom, estar dentro do condomínio traz segurança: 'Ah, vou fechar o olho aqui, a criança tá brincando, mas tá aqui dentro', uma sensação de tranquilidade. Eles tão brincando, mas tá dentro de casa". Ivone antevê que o condomínio como facilitador no convívio futuro com seus pais que "daqui a pouco vão ser idosos; então eu penso, eles estão em casa, tá tranquilo, ninguém vai entrar".

O condomínio-clube delimita assim as fronteiras com o mundo externo, com suas caraterísticas de proteção do mundo exterior. Maria explica: "Estou pagando minha segurança, da minha família. Tem lazer dentro do condomínio sem precisar sair. Nesse mundo doido que a gente vive [...] é bom porque você não precisa estar nesse mundo ruim de hoje, de sair de dentro do condomínio". A questão da segurança é, no entanto, relativizada por Lucas, que mesmo assim valida o condomínio como fora do mundo externo: "Não adianta o condomínio seguro, se o entorno te deixa vulnerável. Não adianta teu carro estar seguro dentro de casa, se você pode ser assaltado na porta de casa”. Assim, o condomínio aparece novamente como extensão da casa, e como mediador entre a segurança da casa e o temor da rua.

\section{- "Chamar os amigos e fazer amizades"}

O condomínio é, ainda, um espaço de sociabilidade, que tanto permite reunir os amigos, como fazer novos amigos. Como os espaços privados dos apartamentos são muito reduzidos, a área de lazer é entendida como uma extensão ampliada do apartamento, permitindo usufruir das instalações com convidados. Brenda usa o salão gourmet de seu condomínio para receber amigos. Já Lucas considera a churrasqueira o espaço ideal para convidar amigos:

[O melhor é a] churrasqueira. Porque a piscina é um espaço mais privativo. Eu não posso levar trinta pessoas para a piscina. É um espaço que eu vou utilizar, então, num momento onde eu vou relaxar. Não que receber amigos não é uma forma de relaxar, é, mas a churrasqueira eu consigo chamar todos eles... Por isso que eu acho mais democrático.

Estabelecer novas relações é visto ainda como parte das possibilidades oferecidas pelo condomínio. Emanuel explica:

No condomínio você não precisa ir à casa do vizinho. Como os apartamentos são pequenos, acho que eles focaram em você não receber suas visitas em casa. Você recebe suas visitas no condomínio. A gente senta, vamos lá para a churrasqueira domingo, falar besteira. Vamos sentar ali para tomar cerveja. Você senta e conversa com as pessoas do condomínio. Não precisa ir à casa delas. Então você chama o vizinho: 'desce 
aí para bater papo'. Então essa coisa que o condomínio ser muito grande, você acaba conseguindo pessoas que têm mais afinidade com você. Você vai fazendo amizade. Não é amigo de verdade, mas você tem aquele relacionamento.

A proximidade entre as pessoas pode não as converter em "amigos de verdade", mas confere à socialização características particulares. Para Marcia, o condomínio é "praticamente um bairro". Jussara destaca o aspecto de coletividade que a infraestrutura do condomínio viabiliza: “A sensação que eu tenho hoje no condomínio é que a coisa é pensada de uma forma mais coletiva. E acaba tendo o interesse de mais pessoas em participar".

No entanto, nem tudo é perfeito, uma vez que, nos espaços comuns, não se tem controle sobre o comportamento dos outros como em casa. Comportamentos considerados inadequados podem tornar a convivência difícil. Por exemplo, moradores que têm cachorro e deixam "muita sujeira" nas áreas comuns; outros que, ao usarem os espaços de lazer, desconsideram o incômodo que podem gerar aos demais ("som alto, pessoas falando muito alto, embriagadas, perdendo as estribeiras"). Fátima fala da "mistura" de pessoas e comportamentos, nem sempre convergentes.

\section{- "Não precisa se deslocar"}

Por fim, destaca-se o significado atrelado à qualidade de vida, devido às áreas de lazer dentro do condomínio permitirem ter uma vida mais saudável com praticidade e comodidade. Há espaços como academias de ginásticas, piscinas, onde podem ser realizadas atividades físicas, ou simplesmente espaços abertos, que permitem a caminhada. Todas estas opções, sem sair do condomínio, são muito apreciadas, associando-se ao significado da segurança, tendo em vista o receio de movimentações desnecessárias fora do condomínio.

\section{SIGNIFICADOS DA AQUISIÇÃO DA MORADIA EM UM CONDOMÍNIO-CLUBE}

A partir do discurso dos informantes foram extraídas cinco categorias de significados atribuídos à casa própria e três relacionadas às áreas de lazer (Quadro 2).

Quadro 2: Significados atribuídos

\begin{tabular}{|l|l|}
\hline Categorias & Exemplos de termos usados pelos informantes \\
\hline Significados associados ao imóvel propriamente dito \\
\hline Aspiração & $\begin{array}{l}\text { "todo mundo quer ter a casa própria”; "sonho de qualquer cidadão", "meu } \\
\text { sonho", "desejo pelo imóvel”, "meta a ser cumprida" }\end{array}$ \\
\hline
\end{tabular}




\begin{tabular}{|c|c|}
\hline Conquista & $\begin{array}{l}\text { "é tudo", "a maior realização", "realização de um sonho", "sensação de } \\
\text { realização incrível", "conquista", "fica num patamar acima", "algo } \\
\text { conquistado com o meu trabalho", "encher a boca para falar que tem", } \\
\text { "orgulho", "tive que batalhar" }\end{array}$ \\
\hline Passagem & $\begin{array}{l}\text { "mudou a minha vida", "um divisor de águas na minha existência", "muito } \\
\text { importante para o meu desenvolvimento", "pontapé inicial", "ponto de } \\
\text { partida para um novo ciclo", "independência", "liberdade", "ter a minha } \\
\text { independência", "questão de independência", "ter as próprias pernas pra } \\
\text { caminhar, próprio tempo, próprio horário" }\end{array}$ \\
\hline $\begin{array}{l}\text { Segurança } \\
\text { (psicológica) }\end{array}$ & $\begin{array}{l}\text { "é meu, ninguém toma", "um chão firme", "estabilidade", "ter o seu, [...] } \\
\text { independente do que possa acontecer", "ninguém pode me tirar", "segurança } \\
\text { de ter o meu lugar" }\end{array}$ \\
\hline Sagrado & "um lugar sagrado" \\
\hline \multicolumn{2}{|c|}{ Associados às áreas comuns } \\
\hline Segurança & $\begin{array}{l}\text { "sem precisar sair", "não precisa estar nesse mundo ruim de hoje", "sem o } \\
\text { medo de ser assaltado", "ninguém vai entrar", "dentro de casa", "sensação } \\
\text { de casa", "ambiente fechado, pessoas conhecidas", "privacidade", }\end{array}$ \\
\hline $\begin{array}{l}\text { Espaço de } \\
\text { sociabilidade }\end{array}$ & $\begin{array}{l}\text { Positivos: "para receber pessoas", "receber amigos", "chamar os amigos", } \\
\text { "fazer amizade", "socializar", "espaço democrático" } \\
\text { Negativos: "falta de respeito, "falta de responsabilidade", “confusão" }\end{array}$ \\
\hline $\begin{array}{l}\text { Qualidade de } \\
\text { vida }\end{array}$ & $\begin{array}{l}\text { "praticidade", "comodidade", "não precisa se deslocar", "para se divertir", } \\
\text { "para se exercitar", "usufruir, correr, brincar", "vida saudável”, "caminhada" }\end{array}$ \\
\hline
\end{tabular}

Os significados de aspiração e conquista se aproximam, mas possuem conotações próprias. Aspiração e conquista apresentam uma sequência temporal: se a casa própria antes era um sonho, algo distante, até mesmo visto como inalcançável, através de esforços e sacrifícios ela se torna possível e se transforma em uma conquista. Assim os dois significados são complementares. Esses temas foram também identificados por Rodrigues (2016).

Os significados de passagem são mais variados, incluindo diversas formas de passagens, particularmente a independência dos pais, o casamento e as mudanças associadas à velhice. Em todas elas, a casa própria tem forte componente simbólico. A passagem da tutela dos pais para a independência é específica dos informantes mais jovens, que associam a posse do imóvel à emancipação econômica e física em relação aos pais. O casamento, também identificado por 
Rodrigues (2016), é um dos fatores que concorrem para a compra da casa própria, demarcando outro tipo de passagem. Por fim, o ninho vazio torna desnecessário uma dada configuração da casa própria, sugerindo mudanças. No caso do nosso estudo, a casa maior é trocada por um apartamento menor, mas com espaços comuns de lazer no condomínio.

Outro significado importante é a segurança. No caso do imóvel em si, é a segurança psicológica que adquire significado, uma vez que se trata de algo que "não pode ser tirado" de quem o possui. No caso da inserção do imóvel em um condomínio fechado, é a segurança física que se impõe, é a proteção contra o mundo externo e seus perigos, não só para o indivíduo como para toda a família, inclusive aqueles que ainda não moram no imóvel, como pais que envelhecem, ou filhos que ainda não nasceram.

Por fim, a casa aparece como local sagrado, conforme discutido por Belk (1988) e Belk, Wallendorf e Sherry (1989). Embora uma única informante mencionasse espontaneamente a natureza sagrada da casa própria, ocorreram menções ao divino, como no caso de Ana: "Graças a Deus a gente conseguiu".

\section{RITUAIS DE POSSE E ARRUMAÇÃO}

Os rituais de posse e arrumação são particularmente importantes, uma vez que, por meio deles, é possível comemorar a aquisição e personalizar o bem, conferindo-lhe significados únicos, por meio de mudanças nos acabamentos e decoração.

Os imóveis adquiridos, assim como as instalações do condomínio, são apresentados a familiares e amigos, gerando sentimentos de orgulho e realização. Trata-se de rituais de posse (McCracken, 1986). Os familiares e amigos "gostam", "se encantam”, “acham bem bacana”. A realização de Maria, para além da conquista alcançada, é expressa pelo prazer de mostrar "o condomínio todo" para quem a visita. Lucas "faz questão" de apresentar "não só o condomínio, como o entorno [...] toda vez que vai alguém diferente" visitá-lo. Apresentar o entorno, pode ser uma forma de "ampliar" a área do apartamento. Segundo Lucas, "o apartamento é muito fácil de mostrar porque é pequeno, então em cinco passos você consegue conhecer o apartamento inteiro. Mas eu levo para conhecer o condomínio, para ver a piscina, para ver os espaços". Espaços externos específicos foram lembrados, como importantes na "excursão" ao apartamento: a área de lazer (Ivone); a área gourmet (Carla); e a quadra e a churrasqueira (Jussara). Jussara diz que "o imóvel virou quase ponto de excursão, porque a gente levava todo 
mundo lá. A gente pegava todos os amigos que estavam aqui pela região da Barra 'Vamos lá ver o apartamento'. Rodava todo o condomínio, área de lazer, mostrava tudo".

Os informantes falam também de rituais de arrumação. Como disse Ana: "A gente queria um teto nosso, que a gente não pagasse aluguel e aí a gente pegava a planta e sonhava em montar ele do nosso jeito". O imóvel só se torna "a sua casa" quando se tem liberdade para "fazer do seu jeito", "fazer obras", personalizando e, assim, traduzindo e estendendo sua individualidade. Comprar um imóvel (em oposição ao aluguel) permite transformá-lo à sua maneira, reconhecendo que é um processo que pode requerer tempo e recursos, e que, portanto, precisa ser feito "aos poucos". A decoração, os móveis e objetos, também desempenham papel importantíssimo na criação da casa. Só depois de passar pelos rituais de arrumação o imóvel se torna, então, "a casa".

A ritualização do processo de aquisição da casa própria não foge aos rituais habituais mencionados por McCracken (1986). Uma vez concluída a aquisição, são feitas as desejadas mudanças no imóvel por meio de rituais de arrumação, que incluem de mudanças físicas a decoração, e que têm a propriedade de transformar o imóvel adquirido em uma "casa", em linha com a pesquisa de Castilhos e Rossi (2009). Antes, depois, ou no decorrer dessas mudanças, realizam-se rituais de posse, que envolvem trazer a família, amigos e conhecidos para comemorações. Mesmo após a aquisição concluída e encerradas as comemorações pela compra, os rituais de posse continuam a ocorrer nas festividades e eventos que a casa, com suas áreas comuns, permite oferecer. Por meio desses rituais, por fim, é completada a transferência de significados dos bens para seus donos, que passam a incorporar a realização de um sonho e uma conquista pessoal, que proporciona independência e segurança na vida, sacramentando passagens e dando acesso ao sagrado. Completa-se, assim, o ciclo previsto por McCracken (1988), através do qual as posses exercem o papel de pontes para que se atinjam os significados que, neste estudo, se associam a ascensão social.

\section{O CONDOMÍNIO-CLUBE COMO ESPAÇO DE CONSUMO}

Os resultados da pesquisa mostram como o condomínio-clube multi-residencial com estrutura de lazer não deve ser visto como simples empreendimento imobiliário, mas como espaço onde convivem oportunidades de subjetividade, possibilidades de relacionamento interpessoal e exposição a uma totalidade social, como salientou Shields (1992), guardando, portanto, similaridades com outros espaços examinados na literatura, como os malls e os 
parques temáticos, entre outros. Em qualquer caso, a vivência desses espaços de consumo é impregnada por significados, alguns dos quais foram desvendados nesta pesquisa.

O consumo simbólico da casa própria assume importância única para os informantes, talvez por significar, mais do que uma propriedade, um espaço social de intimidade, harmonia e acolhimento, como ensina DaMatta (1997). No contexto dos consumidores emergentes que informaram o estudo, a casa própria assume os significados de aspiração, conquista, independência, símbolo da passagem, segurança e um espaço sagrado. A ela se opõe "o mundo ruim lá fora", do qual estamos protegidos quando nos encontramos dentro da casa.

A organização simbólica do espaço emerge do discurso dos informantes (Figura 1), que adquiriram imóveis inseridos em um condomínio-clube, remetendo à obra de DaMatta (1997). Neste espaço, nem sempre as fronteiras se encontram claramente delimitadas. Por vezes, o condomínio é descrito como uma extensão da casa, em oposição à rua ("Dá uma sensação de casa. Estou na minha casa"); por outras, ele é visto como um espaço de fronteira, onde ainda se tem algumas qualidades da "casa", mas onde se convive com estranhos, que podem até ser conhecidos, mas não são "amigos de verdade".

Alguns espaços, nas áreas comuns, são mais facilmente apropriados para se tornarem parte da casa, ao menos de forma temporária, como a churrasqueira, a sala gourmet, ou a quadra de esportes, espaços que podem ser reservados por algum tempo para uso privativo. No entanto, há regras no uso desses espaços, que definem a conduta e requerem disciplina. Algumas são explícitas (como as regras do condomínio), mas outras são implícitas. Além disso, o uso de áreas comuns implica, como afirmou Paterson (2006), uma negociação entre os usuários, que inclui tanto aspectos relacionados ao espaço como ao tempo.

Figura 1 - Organização simbólica dos espaços 


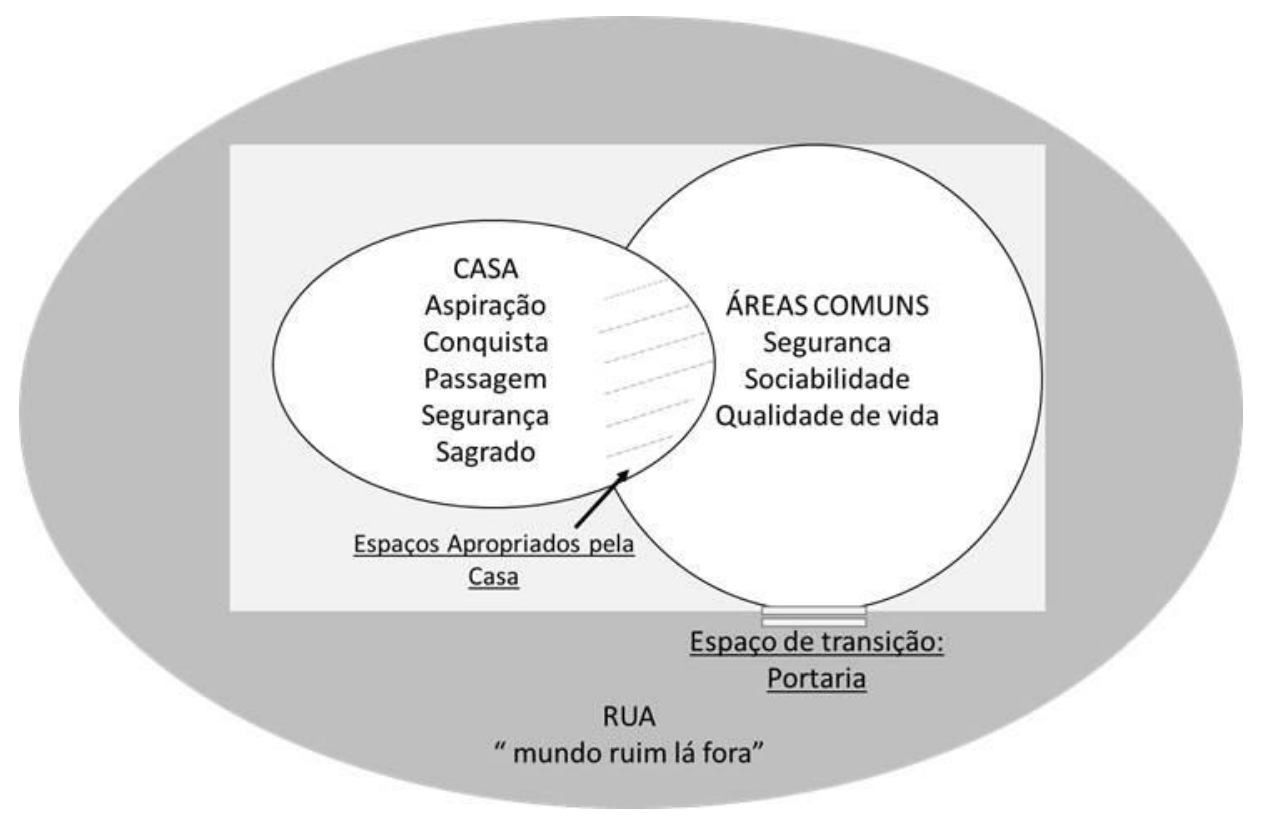

As varandas dos apartamentos são menos um local para receber visitas (como identificou DaMatta, 1997), embora possam ter também essa função, e mais uma conexão com o espaço, a liberdade e a natureza. São também símbolos da própria ascensão social, já que são típicas de imóveis formais, construídos legalmente, e similares aos das classes mais altas. São, como indicou Paterson (2006), marcadores de posição social. Além disso, como observou DaMatta (1997), a varanda é um mediador entre a casa e o mundo lá fora, mas não aquele mundo social ameaçador e sim o mundo natural.

A portaria é o divisor entre o mundo conhecido e protegido da casa e o mundo de fora, que é inseguro e ameaçador, permitindo o controle de quem entra e de quem sai. A existência dessa espécie de portal entre os dois mundos é vista como símbolo de segurança, que transcende a segurança física, trazendo também consigo um elemento moral, já que, de certa forma, estabele as fronteiras entre o bem e o mal, o privado e o público. A proteção, no entanto, implica permanente vigilância, o que levou Shields (1992, p. 3) a reconhecer no próprio mall "um toque sombrio da prisão panóptica Foucaultiana, em que a visibilidade e a vigilância reinam supremas". No condomínio, ao contrário da prisão, a vigilância e a contenção são desejadas pelos residentes, de tal forma que a sensação de segurança adquire elevado valor simbólico.

\section{CONSIDERAÇÕES FINAIS}


Os bens exercem funções simbólicas nas sociedades contemporâneas, podendo ser usados para dizer algo a respeito de quem os possui ou usa. Para os consumidores emergentes, a casa própria pode ser um marcador de aspirações, conquistas e independência, entre outros significados, servindo ainda para demarcar passagens. Em alguns casos, pode ser um marco na história familiar do consumidor, já que frequentemente seus antepassados não tiveram a possibilidade de morar em imóvel próprio, vivendo durante anos sob a instabilidade do pagamento de um aluguel ou em imóveis de propriedade duvidosa, construídos em terrenos que não lhes pertenciam. De forma similar ao que Wang (2016) registrou na China, adquirir a casa própria, em última análise, consolida a ascensão social à classe média.

No passado, apenas os estratos superiores das classes médias e alta tinham acesso ao lazer exclusivo e à segurança derivada do aprisionamento voluntário dentro de um espaço compartilhado. Os condomínios-clube do Programa Minha Casa Minha Vida mimetizem os condomínios de luxo onde vivem os ricos e afluentes, mas são meros reflexos do estilo de vida das elites. Mesmo assim, adquirem significados que expressam as aspirações à moradia digna desse estrato emergente da população brasileira.

Pelas limitações próprias do método escolhido, nosso estudo não pretende fazer generalizações para a população brasileira, nem para a nova classe média. No entanto, a consonância dos achados da pesquisa com outros estudos sugere a possibilidade de generalização analítica. Assim, os achados da pesquisa contribuem para o entendimento de como se dá o consumo simbólico de bens por parte de indivíduos que ascenderam socialmente nas últimas décadas no Brasil e de como os significados desses bens são transferidos. Além disso, o estudo contribui ao investigar um objeto de consumo que ainda não havia recebido a atenção dos pesquisadores, por meio do mapeamento simbólico dos seus espaços e de suas fronteiras. Sob a perspectiva gerencial, a pesquisa traz contribuições para o entendimento do significado, para o consumidor emergente, da aquisição de moradia própria com áreas de lazer em condomínios-clube multifamiliares, podendo ser útil para empresas que atuam neste segmento, como também para os gestores de programas governamentais como o Programa Minha Casa Minha Vida.

\section{REFERÊNCIAS}


ARNOULD, E. J.; THOMPSON, C.J. Consumer culture theory (CCT): twenty years of research. Journal of Consumer Research, v. 31, n. 4, p. 868-882, 2005.

ARNOULD, E. J.; THOMPSON, C.J. Consumer culture theory (and we really mean theoretics): dilemmas and opportunities posed by an academic branding system. In: BELK, R.W.; SHERRY JR, J. Consumer Culture Theory - Research in consumer behavior, v.11 (p. 3-22). London: Elsevier, 2007.

BARBOSA, L. Sociedade de consumo. Rio de Janeiro: Zahar, 2004.

BARROS, C.; ROCHA, E. Lógica de consumo em um grupo de camadas populares: uma visão antropológica de significados culturais. In: ROCHA, A.; SILVA, J. Consumo na base da pirâmide: estudos brasileiros. (p. 31-47). Rio de Janeiro: Mauad X, 2009.

BAUDRILLARD, J. A sociedade de consumo. Lisboa: Edições 70, 1995.

BELLINI, L. P.; ALVARES, L. F. H.-M. Sociedade e consumo: respostas afetivas dos consumidores de baixa renda a perdas involuntárias de bens e posses simbólicos. Rio de Janeiro: Novas Edições Acadêmicas, 2018.

BELK, R.W. Possessions and the extended self. Journal of Consumer Research, v. 15, p. 139-168, 1988.

BELK, R.W.; WALLENDORF, M.; SHERRY, J. The sacred and profane in consumer behavior: theodicy on the odyssey. Journal of Consumer Research, v.16, n.1, p. 1-38, 1989.

CAMPBELL, C. Sociedade de consumo: Eu compro, logo sei que existo: as bases metafísicas do consumo moderno. In: BARBOSA, L.; CAMPBELL, C. (Org.). Cultura, consumo e identidade. (p. 47-64). Rio de Janeiro: Editora FGV, 2006.

CASOTTI, L.M.; SUAREZ, M.C. Dez anos de Consumer Culture Theory: delimitações e aberturas. Revista de Administração de Empresas, v.5 6, n. 3, p. 353-359, 2016.

CASTILHOS, R.; ROSSI, C. E. Subindo o morro: consumo, posição social e distinção entre as famílias de classes populares. In: ROCHA, A.; SILVA, J. Consumo na base da pirâmide: estudos brasileiros. (p. 48-73). Rio de Janeiro: Mauad X, 2009.

COSTA, F. N. Cidadania e cultura: regressão social. Disponível em: <https://fernandonogueiracosta.wordpress.com>. Acesso em: 16 dez. 2016. 
COSTA FILHO, M. C. M.; MOTTA, P. C. M. (2015). Gestão de orçamento nas compras de supermercado da nova classe média. Revista Pensamento Contemporâneo em Administração, v.9, n.4, p. 111-127.

CRESWELL, J. Projeto de pesquisa: métodos qualitativo, quantitativo e misto. 3. ed. Porto Alegre: Artmed, 2010.

CUNHA, V.; HEMAIS, M. W. 'O calçadão é legal': estudo interpretativista sobre os significados associados por consumidores de baixa renda a um polo comercial de rua. Revista Economia \& Gestão, v.18, n.50, p. 44-61, 2018.

DaMATTA, R. A casa e a rua: espaço, cidadania, mulher e morte no Brasil. Rio de Janeiro: Rocco, 1997.

DOUGLAS, M.; ISHERWOOD, B. O mundo dos bens: para uma antropologia do consumo. Rio de Janeiro: Editora UFRJ, 2013.

ECKHARDT, G.M.; BELK, R.W.; WILSON, J.A.J. The rise of inconspicuous consumption. Journal of Marketing Management, v. 31, n. 7/8, p. 807-826, 2015.

FERREIRA, C. C. A casa dos sonhos: necessidades, aspirações, símbolos. 2006. 247 p. Dissertação (Mestrado)- Faculdade de Arquitetura e Urbanismo, Universidade de São Paulo, São Paulo, 2006.

FJP. FUNDAÇÃO JOÃO PINHEIRO. Centro de Estatistica e Informações. Déficit habitacional no Brasil. Disponível em: http://novosite.fjp.mg.gov.br/deficit-habitacional-nobrasil/. Acesso em: 04.03.2020

GEERTZ, C. The interpretation of cultures. New York: Basic Books, 1973.

HEMAIS, M. et al. Economia, marketing e indivíduos de baixa renda: o interesse após uma história de indiferença. Revista de Ciência de Administração, v. 16, n. 39, p. 49-64, 2016.

JULIO, L. F. F.; HEMAIS, M. W. Significados de planos de saúde para consumidores de baixa renda. Revista Pretexto, v.20, n.4, p. 60-74, 2019.

LODI, R. J.; HEMAIS, M. W. (2019). Consumidores de baixa renda e o seu eu estendido em carros: uma pesquisa interpretativista. Revista de Administração da Unimep, v.1, n.2, p.165-186, 2019. 
LUBECK, R. M.; FALLAVENA, L. H. A.; SANTINI, F. O.; SAMPAIO, C. H. Diga-me no que andas e te direi quem és: aspectos de influência nos jovens da classe $\mathrm{C}$ brasileira para adquirir automóveis. Revista Brasileira de Marketing, v.13, n.3, p.17-35, 2014.

MATTOSO, C. L. Q.; LIMA, A. S.; NEVES, L. S. Influência das classes sociais no consumo de lazer entre idosos e jovens. Revista ADM.MADE, v.15, n.2, p. 49-62, 2011.

McCRACKEN, G. Culture and consumption: a theoretical account of the structure and movement of the cultural meaning of consumer goods. Journal of Consumer Research. v.13, n. 1, p. 71-84, 1986.

MICK, D. G.; DeMOSS, M. To me from me: a descriptive phenomenology of self-gifts. Advances in Consumer Research, v. 17, p. 677-682, 1990a.

MICK, D. G.; DeMOSS, M. Self-gifts: Phenomenological insights from four contexts. Journal of Consumer Research, v.17, p. 322-332, 1990 b.

MOREL, A. P. S.; MACEDO, S. B.; SETTE, R. S.; REZENDE, D. C. Simbolismo e extensão do self no consumo de produtos de beleza. Revista Pretexto, v.17, n.1, p. 11-28, 2016.

NASCIMENTO, E. S.; COSTA FILHO, M. C. M.; ALVARES, L. F. H.-M. Significados da educação privada na nova classe média. Revista Pensamento Contemporâneo em Administração, v.11, n.2. p. 32-46, 2017.

NERI, M. A nova classe média: o lado brilhante dos pobres. Rio de Janeiro: FGV/CPS, 2010.

NERI, M. A escalada da desigualdade: qual foi o impacto da crise sobre distribuição de renda e pobreza? Rio de Janeiro: FGV Social, 2019. Disponível em: https://www.cps.fgv.br/cps/bd/docs/A-Escalada-da-Desigualdade-Marcelo-Neri-FGVSocial.pdf.

PATERSON, M. Consumption and everyday life. London: Routledge, 2006.

PONTE, L. F.; MATTOSO, C. Q. Capital cultural e o consumo de produtos culturais: as estratégias de consumo de status entre mulheres da nova classe média. Revista Brasileira de Marketing, v.13, n.6, p. 18-33, 2014.

RITZER, G.; RYAN, M.; STEPNISKY, J. Transformations in consumer settings: landscapes and beyond. In: RATNESHWAR, S.; MICK, D. G. (org.). Inside consumption: consumer motives, goals, and desires. (p.292-308). London: Rouledge, 2005. 
ROCHA, A. R.; ROCHA, A.; ROCHA, E. Classifying and classified: an interpretive study of the consumption of cruises by the "new" Brazilian middle class. International Business Review, v.25, p.624-632, 2016a.

ROCHA, A. R.; ROCHA, A.; ROCHA, E. Rituals of cruise consumption and the 'new' middle class: desiring and 'devouring' maritime cruises. Leisure Studies, v. 36, n.4, p. 1-13, 2016 b.

ROCHA, A.; ROCHA, E. Paradigma interpretativo nos estudos de consumo: retrospectiva, reflexões e uma agenda de pesquisas para o Brasil. Revista de Administração de Empresas, v. 47, n. 1, p. 71-80, 2007.

SCHMIDT, L.E. Consumer rites: the buying and selling of American holidays. Princeton, NJ: Princeton University Press, 1995.

SENNA, S. S.; HEMAIS, M. W. Significados associados a shopping centers por consumidores da classe C. Revista de Administração da Unimep, v.15, n.4, p. 93-116, 2017.

SHERRY, J.F., JR. Gift giving in anthropological perspective. Journal of Consumer Research, v. 10, n. 2, p. 157-168, 1983.

SHIELDS, R. Spaces for the subject of consumption. In SHIELDS, R. (org.). Lifestyle shopping: the subject of consumption. (p. 1-16). London: Routledge, 1992.

RODRIGUES, A. Lar, Doce Lar: os significados do consumo do primeiro imóvel para os jovens geração y da nova classe média brasileira. 2016. 124 p. Dissertação (Mestrado) Programa de Pós-Graduação em Administração, Pontifícia Universidade Católica, Minas Gerais, 2016.

ROOK, D.W. The ritual dimension of consumer behavior. Journal of Consumer Research, v.12, p. 251-264, 1985.

SSATCIOGLU, B.; OZANNE, J. Moral habitus and status negotiation in a marginalized working class neighborhood. Journal of Consumer Research, v.40, p. 692-710, 2013.

TURNER, V.W. O processo ritual: estrutura e antiestrutura. Rio de Janeiro: Vozes, 2013.

WANG, X. Conflicted images: producing and consuming images of the middle class in China's media. In: Marsch, L.L. \& Li, H. (eds.) The middle class in emerging societies: consumers, lifestyles and markets. New York, Routledge, 2016, p.58-81. 
WARNABY, G.; MEDWAY, D. Marketplace icons: shopping malls, Consumption Markets \& Culture, 21:3, 275-282, 2018. 